\title{
OUT OF POCKETS SPENDING AMONG BREAST CANCER WOMEN RECEIVING OUT- PATIENT TREATMENT IN A TERTIARY TEACHING HOSPITAL IN KUALA LUMPUR MALAYSIA
}

\author{
Jamilah Yusoff ${ }^{1}$ and Aniza Ismail ${ }^{1}$ \\ ${ }^{1}$ Community Health Department, Medical Faculty, University Kebangsaan Malaysia,Jln Yaakob Latif Bandar Tun Razak, \\ 56000 Cheras Kuala Lumpur, Malaysia
}

Corresponding author: Aniza Ismail

Email: aniza@ppukm.ukm.edu.my

\begin{abstract}
There is lack of information about the estimates of out-of-pocket (OOP) spending among women diagnosed with breast cancer and effects on their family's financial situation in Malaysia. This study is to determine estimates of out-of-pocket spending among women with breast cancer in HCTM and identify factors that significantly associated with high OOP spending. This cross-sectional study assessed out of pockets spending among breast cancer women in HCTM for breast cancer as out-patient. Sampling unit is a woman who has been diagnosed breast cancer and receiving treatment and follows up in HCTM. A 189 breast cancer women were identified for a 6 months period between July to December 2017. Only those patients who received at least 6 months treatment in HCTM were recruited. Out of pocket spending for treatments for adjuvant therapy and follow up, consultations with other practitioners, care taker fee, equipment and traditional/complementary treatment were collected by face-to-face interview using structured questionnaires. The dependent variable was OOP, analyzed using SSPS v23 for descriptive analysis and both univariate and multivariate analysis. 173 out of 186 women were recruited and only 172 were considered for cost calculation (participation rate, 93.0 \%) in this study. Total out of pocket spending for breast cancer treatment in 2017 was RM 1,037,446.23 with women's total means out of pocket spending was RM6031.66 (SD =/- 495.58). The highest percentage of cost component contributed by cost of adjuvant therapy, RM334,056.00 (30.2\%) followed by traditional/complementary medicine, RM268,278.00 (24.3\%), other expenses/private hospital, RM224,887.00 (20.4\%), transportation RM 79,772.52 (7.2\%), chemotherapy RM67,300.00 (6.1\%), dressing RM54,850.00 (5.0\%), equipment/prosthesis RM50,550.00 (4.6\%) and care taker cost RM24,661.43 (2.2\%). Out of pockets costs from breast cancer in HCTM for 2017 are a burden for women and their family. Financial support provides assistance to the out-of-pocket spending in breast cancer treatment and is able to reduce the financial burden among patients and families.
\end{abstract}

Keywords: out of pocket cost, breast cancer

\section{INTRODUCTION}

Study showed that breast cancer patients had statistically significantly higher OOP as compared to other cancer such as colorectal, lung and prostate cancer $^{1}$. They had higher device costs, family care costs as well and perceived greater financial burden $^{2}$. WHO defined out-of-pocket (OOP) payments as direct payments made by individuals to health care providers at the time of service. Direct costs include cost of using resources for the care of cancer and related sequelae. These include medical direct costs such as clinic fees, adjuvant therapy, and other health care services. These costs are paid by patients and their families as out of pocket and may be paid by third party payer if survivors have insurance coverage ${ }^{3,4}$.
Some prescribed drugs were subsidized to a targeted group such as government servant and their close relatives, elderly and non-capable individual. While non-medical direct costs include those expenses necessary to obtain care such as transportation to hospitals, parking, accommodation and childcare services. Patients and family bear the entire burden of these nonmedical direct costs.

In addition, patients are required to pay for targeted therapy, complementary and alternative medicine (CAM), home nursing care or wigs and prosthesis which are not covered by public health care system. As a result of growing expenses, even patients with insurance may require financial assistance from government or nonprofit national copayment assistance organizations to guarantee 
access to therapy and to mitigate the financial burden of cancer care ${ }^{5}$.

Unable to bear the costs, patients also may tend to applied strategies to defray costs including cut back on leisure activities, reduced spending on food and clothing, used saved savings, took less than the prescribed amount of medication or avoided filling prescribed altogether. Copayment assistance applicants were more likely than nonapplicants to employ at least one of these strategies to defray costs ${ }^{6,7}$.

Monthly out of pocket costs for Malaysia patients with breast cancer receiving treatment in private hospital previously been reported but detail for tertiary center is unknown. Hospital Chancelor Tuanku Muhriz (HCTM) is one of a tertiary hospital and a training centre for breast surgeon, oncologist, radiologist especially in radio-nuclear technology for breast cancer imaging and it became one of a centre for excellent in managing breast cancer. The managing team consists of a group of breast surgeon, pathologist, radiologist, oncologist and its supporting team. It received referral from local area of Kuala Lumpur and all over Malaysia as well, as far as Sabah and Sarawak. Thus, this study will give a picture of out-of-pocket burden among breast cancer women treated in Malaysia and better understanding and consideration of treatment plan in the future. Our objectives were to describe the extent of out of pockets spending among breast cancer women and their family, to identify women at risk of spending higher level out of pocket and to examine the effect of out of pockets spending to women's financial situation.

\section{METHODOLOGY}

This is a cross-sectional study, assessing out of pocket costs among breast cancer women in HCTM.

\section{Sample size}

For this study, the confidence interval was set at 95 percent with surveillance strength $(1-B)$ at 80 percent to estimate the total sample required. Using age-standardized rate (ASR) per 100,000 population, sample size was calculated by statcalc with the estimated frequency of 0.39 percent, so total sample required was 76 . Taking into consideration 10 percent drop off, the overall sample required was 84 .

\section{Subjects}

Breast cancer women treated in HCTM within 6 months period between July to December 2017 were identified. Only those patients who received at least 6 months treatment in HCTM and consented were recruited in this study. The recruitment during 6 months duration were from various wards and clinics including breast clinic, endocrine clinic, oncology clinic, daycare admission for chemotherapy adjuvant and ward as well such as surgical and oncology wards. Potentially eligible participants were identified through admission list to ward and day care, and clinic appointment within recruitment period. Universal sampling was used.

Inclusion criteria include eligible women include those diagnosed breast cancers for at least 6 months to be able to give information on how much they have spent for the treatment, and those who were able to communicate either in English or Malay. Exclusion criteria were women, who were aged less than 18 years old, had other concomitant cancer, unable to participate due to language barrier or mentally incoherent.

\section{Data}

Socio-demographic data include age, race, marital status, occupation, current address, monthly income and out of pocket expenses related to breast cancer. Other cost related information includes sources of money besides regular monthly income such as financial assistance, insurance coverage and subsidy or co-payment by the government or employer. Data collection was collected by face-to-face interview using structured questionnaires about 20 minutes duration.

Out of pocket spending for breast cancer women include both medical and non-medical costs. Medical cost includes hospital bills, consultation fee every follow up visit, purchases of a prosthesis, lab and radiological investigations and adjuvant therapy cost as well such as radiotherapy, chemotherapy, hormonal or biological therapy. Non-medical costs include transportation, parking ticket, accommodation and caretaker payment.

\section{Cost definition used in this study}

Out of pocket cost is defined as all RM amount paid by the women or their spouses as a result of breast cancer and related treatment including consultations from different types of practitioners as well as traditional products and complementary treatment. Hospital treatment cost was a cost incurred for other adjuvant therapy than chemotherapy such as radiotherapy, hormonal or biological therapy received for the last 1 year either received in HUKM or other facilities. Traditional and complementary medicine costs were costs for any form of complementary medicine such as acupuncture therapy, oral supplements etc. 
Equipment costs were the cost of equipment related to breast cancer illness such as fixed bra, bed, wheelchair and any other equipment required after diagnosed breast cancer. Dressing costs were costs incurred by participants for dressing services or buying consumable items for home dressing especially for those with ulcerative breast mass.

Transportation costs for those who travelled with their personal car were based on Google map estimation of distance from current resident address to HCTM. This distance was multiplied by RM0.4 per kilometer, the estimated 2017 rate for car travel considering mean 2017 oil price. For each visit, the amount was multiplied by two to account the return trip and multiplied further by the number of visits. Toll and parking charges were added to total transportation costs. For other transportation methods, we used the exact cost of travelling incurred by patients.

Caretaker costs were the cost paid for hiring the caretaker to take care of participants or their child because of the illness. Other costs include registration fee and cost of service charges in private clinics/hospitals, annual mammograms or other laboratory investigations.

The dependent variable was OOP in Ringgit Malaysia (RM). The total out of pockets for 1 year were estimated with assumptions that patients may receive completed all the 6 cycles of chemotherapy within 2018. All analyses were performed using SPSS v23. The analysis presented as mean and SD. The univariate and multivariate analysis were generated by Annona and chi square test with significant $p$ values taken at 0.05 .

\section{RESULTS}

A total of 186 women with breast cancer were identified during the study period. Out of these, only 173 women were eligible and recruited with respond rate of 93.0 percent. There were 10 women refused to participate in this study and 3 others excluded in this study as they have concomitant other cancer such as thyroid and ovarian cancer. One patient however bears no cost for a year treatment as she had only yearly followed up and only came by walking as her house just nearby the HCTM, thus excluded from the analysis. For costs calculation, total participants were 172 women.

The highest group age of women with breast cancer were seen in 50-59 years old age group (35.5\%) followed by 60-69 years old group (33.1\%), 40-49 years old $(19.2 \%)$, more than 70 years old $(8.1 \%)$ and 30-39 years old (4.1\%). The youngest breast cancer woman in this study was 33 years old lady and the oldest was 84 years old.

The majority of participants were married $(73.8 \%)$, followed by widower (11.0\%) and single both account about $7.6 \%$ respectively. The majority of participants were Malay $(67.4 \%)$ followed by Chinese (25.6\%) and Indian (7.0\%). Regarding educational status, there were $76.8 \%$ were received at least secondary school but there were $18.6 \%$ only received primary school and $4.6 \%$ not to school. About $31.4 \%$ of the women were working while 21.5 $\%$ were never worked and $28.5 \%$ were retired. However, $18.6 \%$ were unemployed during the study period mainly due to the illness and these groups were affected financially by contracting the breast cancer. There were also $57.2 \%$ of women had concomitant illness such as diabetes, hypertension and etc.

In term of treatment received by the participants, there were $16.9 \%$ of women were diagnosed with breast cancer less than 1 year, $53.5 \%$ had been diagnosed between 1 to 5 years, $15.1 \%$ between 5 10 years and $14.5 \%$ were breast cancer survivors more than 10 years. $23.1 \%$ of women were taking traditional and complementary medicines in addition to hospital treatment.

In term of financial status of the participants, about 46.6\% had household income less than RM3000.00, $18.0 \%$ between RM3000-5000, 27.9\% between RM5000-10,000 and only $7.5 \%$ had more than RM10,000 per month. There were 30 participants or $17.4 \%$ who reported that they loss their occupation after diagnosed with breast cancer. In term of having health insurance, only 32 out of 172 participants, or $18.6 \%$ were having health insurance Regarding the payer, $71.5 \%$ were government through guarantee letter either the participants or family members were government workers while only $2.9 \%$ were from private sector. There were $9.9 \%$ were paid by participants own pocket money while $15.7 \%$ receives financial aid from various organizations. The highest mean out of pocket spending was from patients who received financial aid group which was RM15,972.00 followed by patients who pay from their own pocket, RM $12,287.46$. Those who paid by their employer showed less out of pockets usage. 
Table 1a Sociodemographic characteristics of respondents

\begin{tabular}{|c|c|c|c|c|c|c|}
\hline Characteristic & $\begin{array}{l}\text { Total, } \\
\mathrm{N}=172\end{array}$ & $\%$ & Mean OOP & $\mathrm{SD}+/-$ & $\mathrm{t}$ & $p$ value \\
\hline \multicolumn{7}{|l|}{ 1.Age (years) ${ }^{\wedge}$} \\
\hline $30-39$ & 7 & 4.1 & RM24,991.77 & 27142.84 & 1.701 & 0.152 \\
\hline $40-49$ & 33 & 19.2 & RM14,377.93 & 24841.71 & & \\
\hline $50-59$ & 61 & 35.5 & RM9,489.43 & 22501.10 & & \\
\hline $60-69$ & 57 & 33.1 & RM6,535.64 & 16916.60 & & \\
\hline$>70$ & 14 & 8.1 & RM7,133.46 & 16407.22 & & \\
\hline \multicolumn{7}{|l|}{ 2.Marital status^ } \\
\hline Single & 13 & 7.6 & RM10075.08 & 8214.97 & 0.450 & 0.718 \\
\hline Married & 127 & 73.8 & RM10345.58 & 22663.23 & & \\
\hline Divorced & 13 & 7.6 & RM3348.92 & 3529.02 & & \\
\hline Widower & 19 & 11.0 & RM11172.04 & 24494.69 & & \\
\hline \multicolumn{7}{|l|}{ 3. Race ${ }^{\wedge}$} \\
\hline Malay & 116 & 67.4 & RM12006.97 & 24051.56 & 1.867 & 0.158 \\
\hline Chinese & 44 & 25.6 & RM6065.72 & 14093.12 & & \\
\hline Indian & 12 & 7.0 & RM3414.13 & 5702.44 & & \\
\hline \multicolumn{7}{|l|}{ 4.Educational status ${ }^{\wedge}$} \\
\hline Nil & 8 & 4.6 & RM20100.33 & 35001.88 & & \\
\hline Primary school & 32 & 18.6 & RM2805.34 & 4191.07 & 2.854 & $0.039^{\wedge}$ \\
\hline Secondary school & 77 & 44.8 & RM8501.54 & 22189.79 & & \\
\hline $\begin{array}{l}\text { Higher educational } \\
\text { institution }\end{array}$ & 56 & 32.0 & RM14463.22 & 22281.42 & & \\
\hline \multicolumn{7}{|l|}{ 5.Occupational status ${ }^{\wedge}$} \\
\hline Unemployed & 69 & 40.1 & R9545.49 & 13277.75 & 0.827 & 0.532 \\
\hline Self-employed & 4 & 2.3 & RM4205.06 & 7161.44 & & \\
\hline Part-time job & 2 & 1.2 & RM7473.33 & 9843.63 & & \\
\hline Full-time job & 48 & 27.9 & RM13702.61 & 24433.20 & & \\
\hline Retired & 49 & 28.5 & RM2814.67 & 4381.40 & & \\
\hline \multicolumn{7}{|l|}{ 6.Concomitant illness } \\
\hline Yes & 98 & 57.0 & RM11031.54 & 25879.02 & & \\
\hline No & 74 & 43.0 & RM8372.68 & 12729.23 & 4.237 & $0.041^{*}$ \\
\hline
\end{tabular}

*variables were tested by student T-test,

$\wedge$ variables were tested by Anova,

$\neq$ significant $p$-value at $p<0.05$ ( 2 tailed)

Table 1b Duration and type of treatment and financial characteristics of respondents

\begin{tabular}{|c|c|c|c|c|c|c|}
\hline Characteristic & $\begin{array}{l}\text { Total, } \\
\mathrm{N}=172\end{array}$ & $\%$ & Mean OOP & SD+/- & $\mathbf{t}$ & $p$ value \\
\hline \multicolumn{7}{|l|}{$\begin{array}{l}\text { 1.Duration of breast } \\
\text { cancer }^{\wedge}\end{array}$} \\
\hline$<1$ year & 29 & 16.9 & RM19087.73 & 31824.78 & & \\
\hline$\geq 1-5$ year & 92 & 53.5 & RM9343.79 & 19775.83 & 2.230 & 0.068 \\
\hline$\geq 5-10$ year & 26 & 15.1 & RM3224.52 & 5415.07 & & \\
\hline$\geq 10-15$ year & 16 & 9.3 & RM6043.19 & 8116.90 & & \\
\hline$\geq 15$ year & 9 & 5.2 & 11885.24 & 30643.86 & & \\
\hline \multicolumn{7}{|l|}{ 2. Type of treatment } \\
\hline \multicolumn{7}{|l|}{ Endocrine therapy } \\
\hline Yes & 121 & 70.3 & 8823.04 & 17345.36 & & \\
\hline No & 51 & 29.7 & 12413.36 & 28468.87 & 1.026 & 0.313 \\
\hline \multicolumn{7}{|l|}{ Chemotherapy } \\
\hline Yes & 137 & 79.2 & 11552.26 & 23442.29 & 4.066 & $0.045^{*}$ \\
\hline No & 36 & 20.8 & 3598.93 & 5608.92 & & \\
\hline
\end{tabular}




\begin{tabular}{|c|c|c|c|c|c|c|}
\hline \multicolumn{7}{|l|}{ Radiotherapy } \\
\hline Yes & 121 & 70.3 & 8359.30 & 19909.83 & \multirow[t]{2}{*}{2.128} & \multirow[t]{2}{*}{0.146} \\
\hline No & 51 & 29.7 & 13513.65 & 23903.28 & & \\
\hline \multicolumn{7}{|l|}{ Surgery } \\
\hline Yes & 163 & 94.8 & 20992.43 & 20992.97 & \multirow[t]{2}{*}{0.180} & \multirow[t]{2}{*}{0.672} \\
\hline No & 9 & 5.2 & 12818.53 & 26490.43 & & \\
\hline \multicolumn{7}{|l|}{$\begin{array}{l}\text { Traditional/complementary } \\
\text { medicine }\end{array}$} \\
\hline Yes & 41 & 23.8 & 18717.16 & 29059.77 & \multirow[t]{2}{*}{9.788} & \multirow[t]{2}{*}{$0.002^{*}$} \\
\hline No & 131 & 76.2 & 7124.16 & 17345.82 & & \\
\hline \multicolumn{7}{|l|}{$\begin{array}{l}\text { 3. Household income/month } \\
(\mathrm{RM})^{\wedge}\end{array}$} \\
\hline$\leq 1000$ & 29 & 16.9 & 3212.89 & 5865.05 & \multirow[t]{5}{*}{1.968} & \multirow[t]{5}{*}{0.102} \\
\hline$>1000-3000$ & 51 & 29.7 & 8906.52 & 20499.19 & & \\
\hline$>3000-5000$ & 31 & 18.0 & 11374.89 & 30400.69 & & \\
\hline$>5000-10,000$ & 48 & 27.9 & 10613.60 & 18219.37 & & \\
\hline$>10,000$ & 13 & 7.5 & 22399.22 & 26328.38 & & \\
\hline \multicolumn{7}{|l|}{ 4.Occupational loss } \\
\hline Yes & 30 & 17.4 & 6740.68 & 9472.67 & \multirow[t]{2}{*}{0.797} & \multirow[t]{2}{*}{0.373} \\
\hline No & 142 & 82.6 & 10552.45 & 22928.76 & & \\
\hline \multicolumn{7}{|l|}{ 5. Health Insurance } \\
\hline Yes & 32 & 18.6 & RM12146.54 & 17275.09 & \multirow[t]{2}{*}{0.444} & \multirow[t]{2}{*}{0.506} \\
\hline No & 140 & 81.4 & RM9371.28 & 22059.08 & & \\
\hline \multicolumn{7}{|l|}{ 6.Payer ${ }^{\wedge}$} \\
\hline Own pocket & 17 & 9.9 & 12287.46 & 35811.93 & \multirow[t]{4}{*}{1.110} & \multirow[t]{4}{*}{0.347} \\
\hline Employer (private) & 5 & 2.9 & 4550.37 & 4661.38 & & \\
\hline Employer (government) & 123 & 71.5 & 8437.29 & 17244.04 & & \\
\hline Financial aid & 27 & 15.7 & 15972.00 & 26823.32 & & \\
\hline 7.Financial sources ${ }^{\wedge}$ & & & & & & \\
\hline Baitul Mal & 5 & 2.9 & 7151.40 & 6712.40 & 1.931 & 0.051 \\
\hline Caregiver & 1 & 0.6 & 1349.60 & 0 & & \\
\hline Church & 1 & 0.6 & 10350.00 & 0 & & \\
\hline Family & 16 & 9.3 & 15155.66 & 28620.59 & & \\
\hline Friends & 2 & 1.2 & 2833.57 & 2197.08 & & \\
\hline Selling property & 1 & 0.6 & 89260.80 & 0 & & \\
\hline Social department & 1 & 0.6 & 7620.00 & 0 & & \\
\hline MAKNA & 2 & 1.2 & 21863.20 & 11833.01 & & \\
\hline Salary & 142 & 82.6 & 8898.75 & 20107.93 & & \\
\hline Zakat & 1 & 0.6 & 825.00 & 0 & & \\
\hline 8.Saving affected & & & & & & \\
\hline Yes & 42 & 24.4 & RM17553.61 & 30687.75 & 7.519 & $0.007^{*}$ \\
\hline No & 130 & 75.6 & RM7411.00 & 16521.78 & & \\
\hline $\begin{array}{l}\text { 9.Problem buying basic } \\
\text { needs }\end{array}$ & & & & & & \\
\hline Yes & 19 & 11.0 & RM7178.60 & 18621.74 & 0.346 & 0.557 \\
\hline No & 154 & 89.0 & RM10224.02 & 21565.56 & & \\
\hline 10.Property affected & & & & & & \\
\hline Yes & 12 & 7.0 & RM4173.55 & 7368.01 & 0.934 & 0.335 \\
\hline No & 160 & 93.0 & RM10316.16 & 21873.18 & & \\
\hline 11. Health expenditure & & & & & & \\
\hline$<20 \%$ & 128 & 74.4 & 3274.43 & 5218.88 & $t=-$ & $0.000^{*}$ \\
\hline$>20 \%$ & 44 & 25.6 & 29125.93 & 34690.56 & 8.209 & \\
\hline
\end{tabular}

*variables were tested by student T-test,

^ variables were tested by Anova

$\neq$ significant $p$-value at $p<0.05$ (2 tailed) 


\section{Out of Pocket expenses}

Univariate analysis showed that educational status significantly associated with mean cost of out of pocket. Those with no education and higher educational institutions showed significantly higher out of pocket with yearly mean cost of RM20,100.30 and $R M 14,463.22$ respectively $(p=0.039)$. Other sociodemographic factors showed no association with the total out of pocket costs. To explain why those with uneducated were spending more out of pockets, we found those who received financial assistance such as from family members, church and from MAKNA spend higher mean out of pockets compared to those with monthly income. Those received financial assistance from family members had mean OOP of RM15155.66, from church RM10350.00 and MAKNA RM21,863.20. While those with higher educational status definitely will spend money as long as it was affordable.

Those with concomitant illness showed higher out of pocket costs, with yearly mean of RM11,031.54 compared to no concomitant illnesses RM 8,372.68 $(p=.0410)$. This is of course due to additional cost spending for follow up for their medical illnesses. In terms of type of treatment, those who received chemotherapy and traditional/complementary medicine showed significantly higher out of pocket spending. Patients who received chemotherapy spent RM11,552.26 $(p=0.045)$ mean a year while patients who took traditional and complementary medicine spent RM18,717.16 ( $p=0.002)$.

For financial data, low socioeconomic group spent less out of pocket and higher socioeconomic groups spending more but statistically no significant association seen. Among occupational status, there were higher OOP spending among women who works full time job (RM13,702.61) compared to unemployed (RM9545.49), self-employed (RM4205.06) part-time job (RM7473.33) and the lowest spending among retired participants (RM2814.67) . However, the mean different between these groups were not significant statistically. There were 18.6 percent with health insurance were showed higher out of pockets with mean RM12,146.54 compared to those without health insurance, RM9,371.28. Regarding the payer, our finding showed participants who spend their own pocket money for treatment of breast cancer and those received financial aid were spending more compared to those paid by government/private employer. However, no significant association seen for all financial variables with the out-of-pocket spending

\section{COST COMPONENT}

The cost components are as listed in Table 2. One year out of pocket spending involving 172 breast cancer women in this study was RM1,037,446.23. The highest percentage of cost component was contributed by cost of adjuvant therapy, RM334,056.00 (30.2\%), followed by traditional and complementary medicine costs, RM 268,278.00 (24.3\%), other expenses/private hospital costs, RM224,887.00 (20.4\%), transportation cost, RM79,722.52 (7.2\%), chemotherapy RM 67,300.00 (6.1\%), dressing RM54,850.00 (5.0\%), equipment and prosthesis RM50,550.00 (4.6\%) and care taker RM24, 661.43 (2.2\%). Participants spend a mean total out of pocket expenses of RM6029.39 (SD+/RM495.58) a year. The highest mean cost was chemotherapy with the mean costs RM16, 825 (SD+ / RM21,720.09), followed by dressing RM4986.36 ( $S D=/-R M 5879.62)$ and adjuvant therapy RM4985.91 (SD+/- 9444.54). Chemotherapy contributes only $6.5 \%$ of total cost component but it was the highest mean cost among all other cost component because of expensive nature of the drug. In Malaysia, cost of trastuzumab alone was estimated around RM42,000 for 6 cycles not including others supplementary drug.

\section{DISCUSSION}

This cross-sectional study examined the OOP health spending on breast cancer as out-patient in Malaysia, specifically in HCTM. The result indicate that one year mean out of pocket cost was RM1,037,446.23 The highest percentage of cost component was contributed by cost of medicine both adjuvant therapy and traditional/complementary medicine. Participants spend a mean total out of pocket expenses of RM6031.66 (SD+/- RM495.58) in one year or mean of RM535.06 per month. The highest mean cost was chemotherapy with the yearly mean costs RM16,825 (SD+/-RM21,720.09), followed by dressing RM4986.36 (SD=/-RM5879.62) and adjuvant therapy RM4985.91 (SD+/- 9444.54). The finding was consistent with previous study found that a copay for chemotherapy drugs is a financial hardship for a significant number of patients ${ }^{5}$ due to its expensive prize. Another study found high need for financial assistance among breast cancer patients in Cairo and they had great difficult affording medications ${ }^{8}$. In addition, nearly half were classified as food insecure and one-third had difficulty affording transportation costs. 
Table 2: Total out of pocket expenses and its components

\begin{tabular}{|c|c|c|c|c|c|}
\hline Costs & $\begin{array}{l}\text { Freq } \\
(\mathrm{N})\end{array}$ & Min, $\max (\mathrm{RM})$ & SD+/- (RM) & Total cost /year & (\%) \\
\hline $\begin{array}{l}\text { Transportation } \\
\text { costs }\end{array}$ & 167 & $0.00-6,969.60$ & 973.17 & $79,772.52$ & 7.2 \\
\hline $\begin{array}{l}\text { Adjuvant } \\
\text { therapy }\end{array}$ & 67 & $75.00-48600.00$ & 9444.54 & $334,056.00$ & 30.2 \\
\hline TCM & 74 & $180.00-46656.00$ & 7047.79 & $268,278.00$ & 24.3 \\
\hline $\begin{array}{l}\text { Equipment } \\
\text { prosthesis }\end{array}$ & 50 & $120.00-7,100.00$ & 1447.56 & $50,550.00$ & 4.6 \\
\hline Dressing costs & 11 & $900.00-18,000.00$ & 5879.62 & $54,850.00$ & 5.0 \\
\hline $\begin{array}{l}\text { Others/private } \\
\text { practice }\end{array}$ & 61 & $30.00-12,130.00$ & 120.00 & $224,887.00$ & 20.4 \\
\hline Care taker costs & 11 & $1080.00-9600.00$ & 937.38 & $24,661.43$ & 2.2 \\
\hline Chemotherapy & 4 & $2400.0-48600.0$ & $21,720.09$ & $67,300.00$ & 6.1 \\
\hline $\begin{array}{l}\text { Total out of } \\
\text { pocket cost } \\
2017\end{array}$ & 172 & $0.00-18,000.00$ & 495.58 & $1,037,446.23$ & 100.0 \\
\hline
\end{tabular}

In term of sociodemographic factor, higher socioeconomic group spend significantly higher out of pocket. Higher household income showed higher OOP which is similar to other study 9 . Several studies found lower income group associated with lower $\mathrm{OOP}$ and a factor contributing to financial toxicity ${ }^{10}$ and higher OOP burden ${ }^{11}$ while the proportion of households facing catastrophic OOP health payments were more prevalent in poor income states and aggravate the prevalence and intensity of poverty by the need to pay for health care services $^{12}$.

Younger age women with breast cancer in this study showed higher OOP as compared to older age group which is similar to other studies ${ }^{5,11}$. Previous study showed younger age is a factor suggestive of contributing to higher OOP costs and OOP burden as well as other factors such as lower income, time in survivorship from diagnosis, use of supportive services $^{11}$, stage at diagnosis and black women ${ }^{13}$. There was no significant difference of mean between races in this study however, study ${ }^{13}$ showed effects of financial burden among minority Black patients with breast cancer, who shoulder a greater burden of poor cancer outcomes with higher mortality and lower initiation of and adherence to recommended treatments, which may be closely related to their inability to pay for care. Study comparing OOP among Australians found indigenous people with cancer had lower OOP expenditure but also accessed fewer Medicare services compared to non-indigenous counterparts.

They were less likely to access primary health care or even specialist attendances, pathology tests and diagnostic imaging14. Racial/ethnic disparities also seen among ethnic minorities towards adherence to adjuvant endocrine therapy and it were largely explained by women's differences in socioeconomic status and out-of-pocket medication costs. Blacks had significantly lower adjusted odds of adherence than non-Hispanic whites when they initiated AET therapy with tamoxifen 15. In this study, higher OOP expenses were seen in a participant who had health insurance and those who received financial aid as compared to those who pay with their own pocket money and those paid by the employer. This reflects that the financial capacity to utilize healthcare services is available among those with financial security or supportive services. Availability of government subsidies help ease out the financial burden, thus allow them to seek appropriate treatment and utilize the financial services well for themselves or their family members. Thus, the lower OOP expenses seen for those with government and private employer coverage. However, the problem with health insurance when greater proportion of costs has been shifting to patients in the form of higher premiums, deductibles, and tiered formularies ${ }^{16}$. These could be the other reason for higher OOP among participants who had health insurance. Higher expenses seen among breast cancer women who were private health insurance holders compared to women without private health insurance ${ }^{17}$. Most of OOP spending came from direct medical expenses.

Household spending changes in a small proportion as they loss of income due to the illness. Wage losses were shown to be the driving factor for deterioration in the family's financial situation 
among early breast cancer patients ${ }^{18}$. Small number of patients had no money to spend on their basic needs and some others had to cut their savings or sell property in order to compensate for the treatment costs. An average of three economic burden events including changes in income and economic lifestyle, borrowing money or using up savings, or in general sacrificing plans like vacations or other events ${ }^{19}$. Evidence-based list of harms that patients experience as a result of cancer treatmentrelated out of pocket cost such as greater risk of mortality, cutting back leisure activity and spending less to defray expenses, struggling on medical bills or defaulted payment ${ }^{20}$, reduction of quality of life and cutting expenses on medication and noncompliance ${ }^{16}$ The proportion of breast cancer survivors also reported change in motivation, productivity, days missed from work but increase in insurance premiums ${ }^{5}$.

In ensuring the continuity of treatment in a financial constraint condition, patient compensate their financial burden by obtaining financial assistant from family members, relatives and friends, NGO's and other related funders. In this study, we can see the financial burden of the patients also affecting the family such as parents and siblings, relatives and friends. Targeted exemption of certain amount of health services for government servants, disable people and elderly from official payments help to reduce OOP. However, for poor patients still need funding from cancer related funder such as Malaysia Cancer Association (MAKNA) or social funder such as Jabatan Agama Islam (JAIM) or Social Department (JKM).

Other strategies to reduce OOP among breast cancer is to cut or abolish user fees and charges in public health facilities at least for targeted group such as the poor group. This might help those who are non-government servant and poor who depends solely on their monthly income. Targeted and exemption a range of health services may also extend into incorporating TCM as a treatment option in HCTM for breast cancer patients, thus offering effective and safe TCM treatment while avoiding unnecessary OOP expenditures.

\section{CONCLUSION}

This study describes OOP expenses and financial impact among breast cancer women undergoing breast cancer treatment. Out of pockets costs from breast cancer in HCTM for 2017 are a burden for women and their family. Medicine is the most vital component of OOP, account for a substantial part of total healthcare expenditure. The high OOP spending may give rise to catastrophic health expenditure and risk of impoverishment. Financial assistant received by patients is necessary to ensure continuity of treatment.

\section{Limitation}

Patients who their payer paid for them or insurance covering they payment were unaware of exact cost of treatment they received thus the cost data given by them may not accurate and missing.

Patients was to recall the cost they spend for the past 3 months and it might different from actual cost due to recall bias.

The OOP spending reported in this study however much lower than actual burden incurred because the cost subsidized by the government or paid by the health insurance or other payers were under reported.

\section{Acknowledgements}

We would like to thank the Dean of the Faculty of Medicine (The National University of Malaysia) for the approval, and all contributing staff especially the Surgical and Oncology department for the assistance during data collection. Special thanks to EuroQol organization for the permission of EQ5D5L questionnaires.

\section{Funding}

This paper is part of the study entitled "The Economic Burden of Breast Cancer in Universiti Kebangsaan Malaysia Medical Center", supported by The National University of Malaysia (Grant No: GUP2016-037).

Availability of data and material: (Not applicable)

Ethical approval and consent to participants:

This study was approved by The National University of Malaysia (Ethic code No: FF-2017-291). Informed consent was obtained from all patients prior to recruitment.

Conflict of interest: There was no conflict of interest.

\section{REFERENCES}

1. Longo, C. J., \& Bereza, B. G. (2011a). A Comparative Analysis of Monthly Out-OfPocket Costs for Patients with Breast Cancer as Compared with Other Common Cancers in Ontario, Canada. Current Oncology, 18(1).

2. Longo, C. J., \& Bereza, B. G. (2011b). Monthly OOP Cost for Breast Cancer Patients Basic Research in Cancer. A Comparative Analysis of Monthly Out-Of-Pocket Costs for Patients with Breast Cancer as Compared 
with Other Common Cancers in Ontario, Canada. Current Oncology, 1-8.

3. https://www.who.int/health_financing/to pics/financial-protection/out-of-pocketpayments/en/

4. Yin, N.A., Amrizal, M. N.,Aniza, I., Syed ,M.A.(2020). Determining the Cost and Length of Stay at Intensive Care Units and the Factors Influencing Them in a Teaching Hospital in Malaysia. 21,149-156.

5. Rajurkar, S. P., Presant, C. A., Bosserman, L. D., \& McNatt, W. J. (2011). A Copay Foundation Assistance Support Program for Patients Receiving Intravenous Cancer Therapy. Journal of Oncology Practice, 7(2), 100-102.

6. Zafar, S. Y., Peppercorn, J. M., Schrag, D., Taylor, D. H., Goetzinger, A. M., Zhong, X., \& Abernethy, A. P. (2013). The Financial Toxicity of Cancer Treatment: A Pilot Study Assessing Out-of-Pocket Expenses and the Insured Cancer Patient's Experience. The Oncologist, 18(4), 381-390.

7. Aung, Y.N., Nur, A.M., Ismail, A., Aljunid, S.M. (2019). Characteristics and Outcome of High-Cost ICU Patients. Clinicoecon Outcomes Res., 11,505-513.

8. Gany, F., Ayash, C., Raad, N., Wu, M., Roberts-Eversley, N., Mahmoud, H., Fouad, Y., Fahmy, Y., Asar, H., Salama, A., \& ElShinawi, M. (2020). Financial and food security challenges of Egyptian women undergoing breast cancer treatment. Support Care Cancer. 2020 Dec;28(12):5787-5794.

9. Ahmadi, F., Farrokh-Eslamlou, H., Yusefzadeh, H., \& Alinia, C. (2021). Incidence of household catastrophic and impoverishing health expenditures among patients with Breast Cancer in Iran. BMC Health Services Research, 21(1), 1-9.

10. Politi M. C., Yen R. W., Elwyn G., O'Malley A. J., Saunders C. H., Schubbe D., Forcino R., Durand M. A. Women Who Are Young, Non-White, and with Lower Socioeconomic Status Report Higher Financial Toxicity up to 1 Year After Breast Cancer Surgery: A Mixed-Effects Regression Analysis. Oncologist. 2021 Jan;26(1):e142-e152
11. Pisu, M., Azuero, A., Benz, R., McNees, P., \& Meneses, K. (2017). Out-of-pocket costs and burden among rural breast cancer survivors. Cancer medicine, 6(3), 572-581.

12. Ghosh, S. (2011). Catastrophic Payments and Impoverishment due to Out-of-Pocket Health Spending. Economic and Political Weekly, 46(47), 63-70.

13. Wheeler, S. B., Spencer, J. C., Pinheiro, L. C., Carey, L. A., Olshan, A. F., \& ReederHayes, K. E. (2018). Financial Impact of Breast Cancer in Black Versus White Women. Journal of clinical oncology: official journal of the American Society of Clinical Oncology, 36(17), 1695-1701.

14. Callander, E., Bates, N., Lindsay, D., Larkins, S., Topp, S. M., Cunningham, J., Sabesan, S., \& Garvey, G. (2019). Long-term out of pocket expenditure of people with cancer: Comparing health service cost and use for indigenous and non-indigenous people with cancer in Australia. International Journal for Equity in Health, 18(1), 1-11.

15. Farias, A. J., \& Du, X. L. (2017). Association between out-of-pocket costs, race/ethnicity, and adjuvant endocrine therapy adherence among medicare patients with breast cancer. Journal of Clinical Oncology, 35(1), 86-95.

16. Zafar, S. Y. (2016). Financial Toxicity of Cancer Care: It's Time to Intervene. Journal of the National Cancer Institute, 108(5), 2427.

17. Breast Cancer Network Australia. (2017). The financial impact of breast cancer. 1-32.

18. Lauzier, S., Levesque, P., Mondor, M., Drolet, M., Coyle, D., Brisson, J., Masse, B., Provencher, L., Robidoux, A., \& Maunsell, E. (2013). Out-of-pocket costs in the year after early breast cancer among canadian women and spouses. Journal of the National Cancer Institute, 105(4), 280-292.

19. Meneses, K., Azuero, A., Hassey, L., McNees, P., \& Pisu, M. (2012). Does economic burden influence quality of life in breast cancer survivors? Gynecologic Oncology, 124(3), 437-443. 
20. Wharam, J. F., Ross-Degnan, D., \& Rosenthal, M. B. (2013). The ACA and HighDeductible Insurance - Strategies for Sharpening a Blunt Instrument. New England Journal of Medicine, 369(16), 14811484. 